\title{
Author Correction: Squaramide-based synthetic chloride transporters activate TFEB but block autophagic flux
}

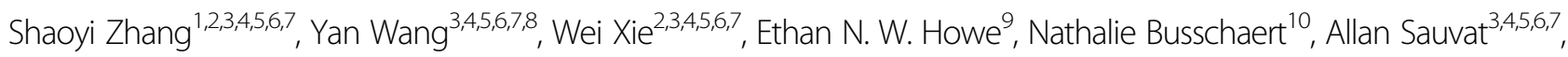
Marion Leduc 3,4,5,6,7, Lígia C. Gomes-da-Silva 3,4,5,6,11, Guo Chen ${ }^{3,4,5,6,7}$, Isabelle Martins ${ }^{3,4,5,6,7}$, Xiaxing Deng ${ }^{1}$, Luigi Maiuri $^{12,13}$, Oliver Kepp (1) $3,4,5,6,7$, Thierry Soussi $\mathbb{B}^{3,4,5,6,7,14}$, Philip A. Gale ${ }^{9}$, Naoufal Zamzami ${ }^{3,4,5,6,7}$ and Guido Kroemer $3,4,5,6,7,15,16$

\section{Correction to: Cell Death \& Disease}

https://doi.org/10.1038/s41419-019-1474-8

published online 11 March 2019
In the version of this article originally submitted, it was stated that the first three authors (Shaoyi Than, Yan Wang, Wei Xie) had contributed equally. However, in the published version this information was missing.

This has been corrected in both the PDF and HTML versions of the Article.

Published online: 03 April 2019

\footnotetext{
Correspondence: Naoufal Zamzami (zamzami66@gmail.com) or

Guido Kroemer (kroemer@orange.fr)

'Department of Surgery, Ruijin Hospital, Shanghai JiaoTong University School of Medicine, Shanghai, China

${ }^{2}$ Faculty of Medicine, University of Paris Sud-Saclay, Kremlin-Bicêtre, France

${ }^{3}$ Metabolomics and Cell Biology Platforms, Gustave Roussy Cancer Campus, Villejuif, France

${ }^{4}$ Centre de Recherche des Cordeliers, INSERM U1 138 Paris, France

${ }^{5}$ Université Paris Descartes, Sorbonne Paris Cité, Paris, France

${ }^{6}$ Gustave Roussy Comprehensive Cancer Center, Villejuif, France

${ }^{7}$ Sorbonne Université, UPMC Univ Paris, Paris, France

${ }^{8}$ Department of Radiation Oncology, Fudan University Shanghai Cancer Center, Shanghai, China

${ }^{9}$ School of Chemistry, The University of Sydney, Sydney, NSW 2006, Australia

${ }^{10}$ Chemistry Department, University of Southampton, Southampton, UK

${ }^{11}$ Chemistry Department, University of Coimbra, Coimbra, Portugal

${ }^{12}$ European Institute for Research in Cystic Fibrosis, Division of Genetics and

Cell Biology, San Raffaele Scientific Institute, Milan, Italy

${ }^{13}$ Department of Health Sciences, University of Piemonte Orientale, Novara, Italy

${ }^{14}$ Department of Oncology-Pathology, Cancer Center Karolinska (CCK),

Karolinska Institutet, Stockholm, Sweden

${ }^{15}$ Pôle de Biologie, Hôpital Européen Georges Pompidou, APsupp-HP, Paris,

France

${ }^{16}$ Department of Women's and Children's Health, Karolinska University

Hospital, Stockholm, Sweden

These authors contributed equally: Shaoyi Zhang, Yan Wang, Wei Xie.

These authors jointly supervised this work: Naoufal Zamzami, Guido Kroemer.
}

(c) (i) Open Access This article is licensed under a Creative Commons Attribution 4.0 International License, which permits use, sharing, adaptation, distribution and reproduction in any medium or format, as long as you give appropriate credit to the original author(s) and the source, provide a link to the Creative Commons license, and indicate if changes were made. The images or other third party material in this article are included in the article's Creative Commons license, unless indicated otherwise in a credit line to the material. If material is not included in the article's Creative Commons license and your intended use is not permitted by statutory regulation or exceeds the permitted use, you will need to obtain permission directly from the copyright holder. To view a copy of this license, visit http://creativecommons.org/licenses/by/4.0/. 